\title{
Developing Effective Learning Exercises in the Geosciences: Utilizing Online Databases and Data Repositories
}

Brown, Kenneth. L. (kenneth.brown1@mail.wvu.edu)

ABSTRACT

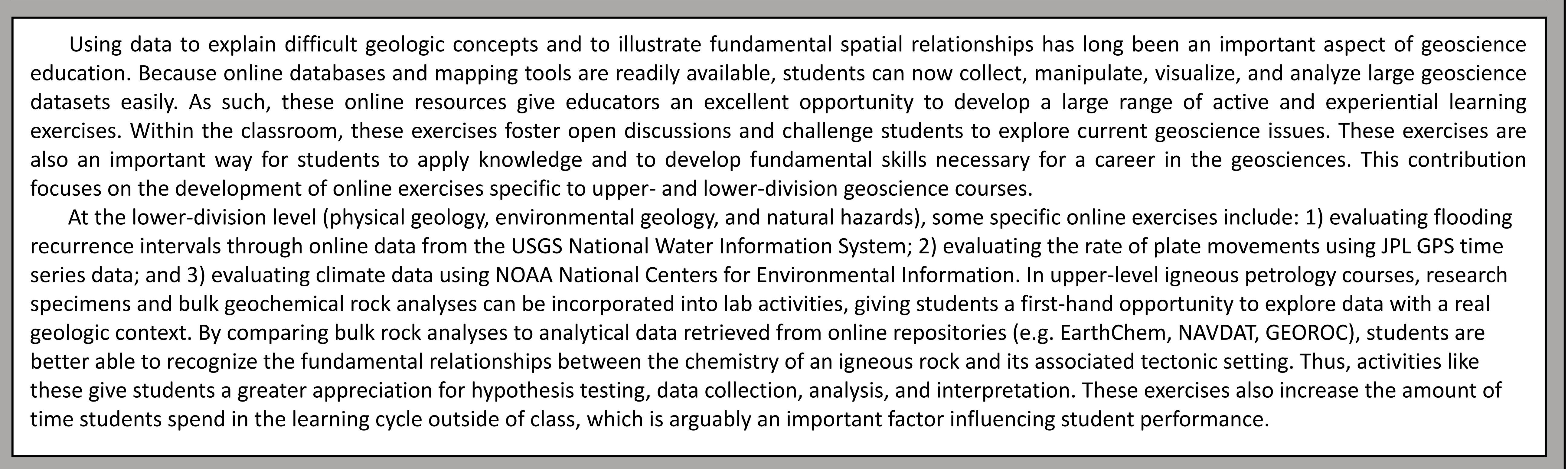

TEACHING OBJECTIVE

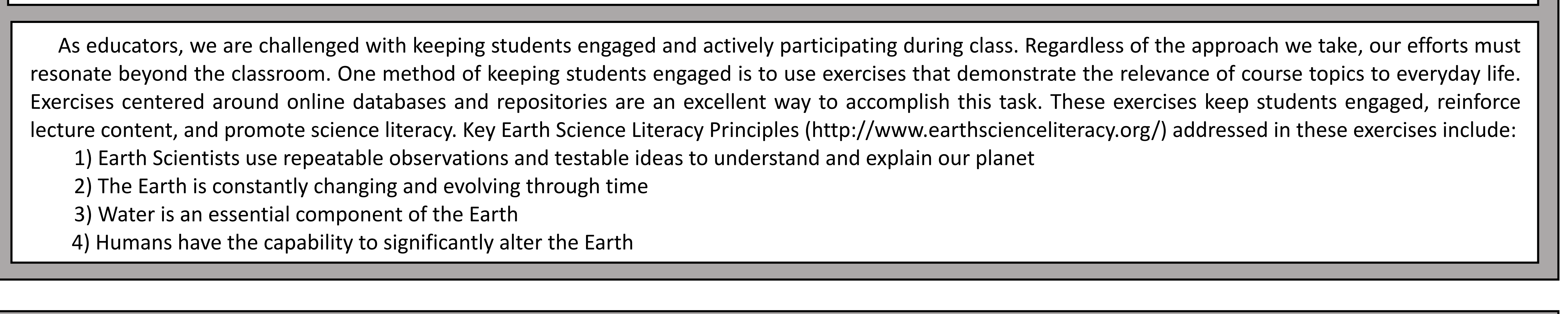

OWER-DIVISION EXERCISE

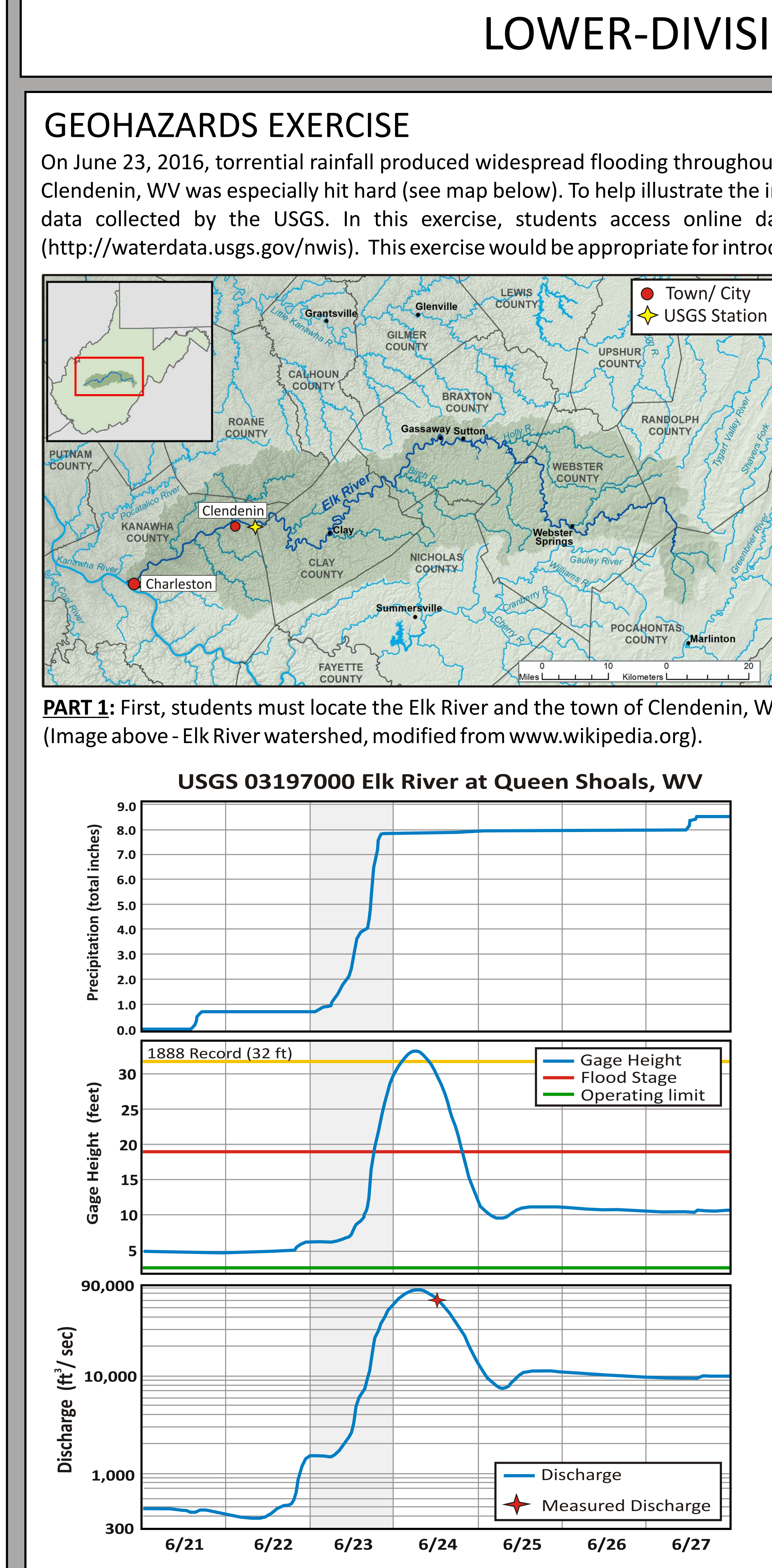

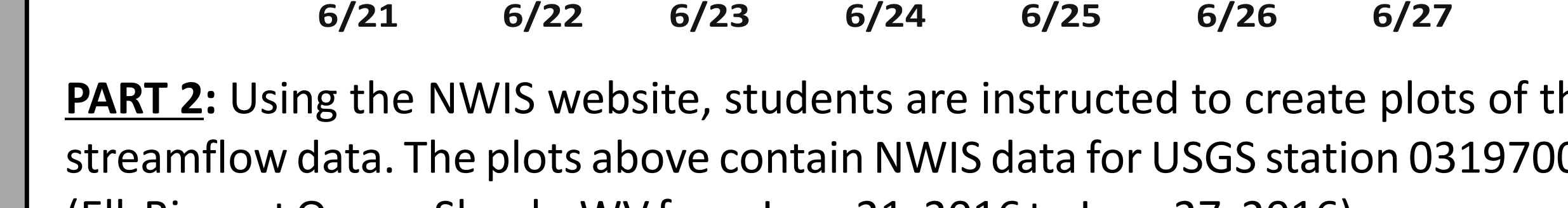

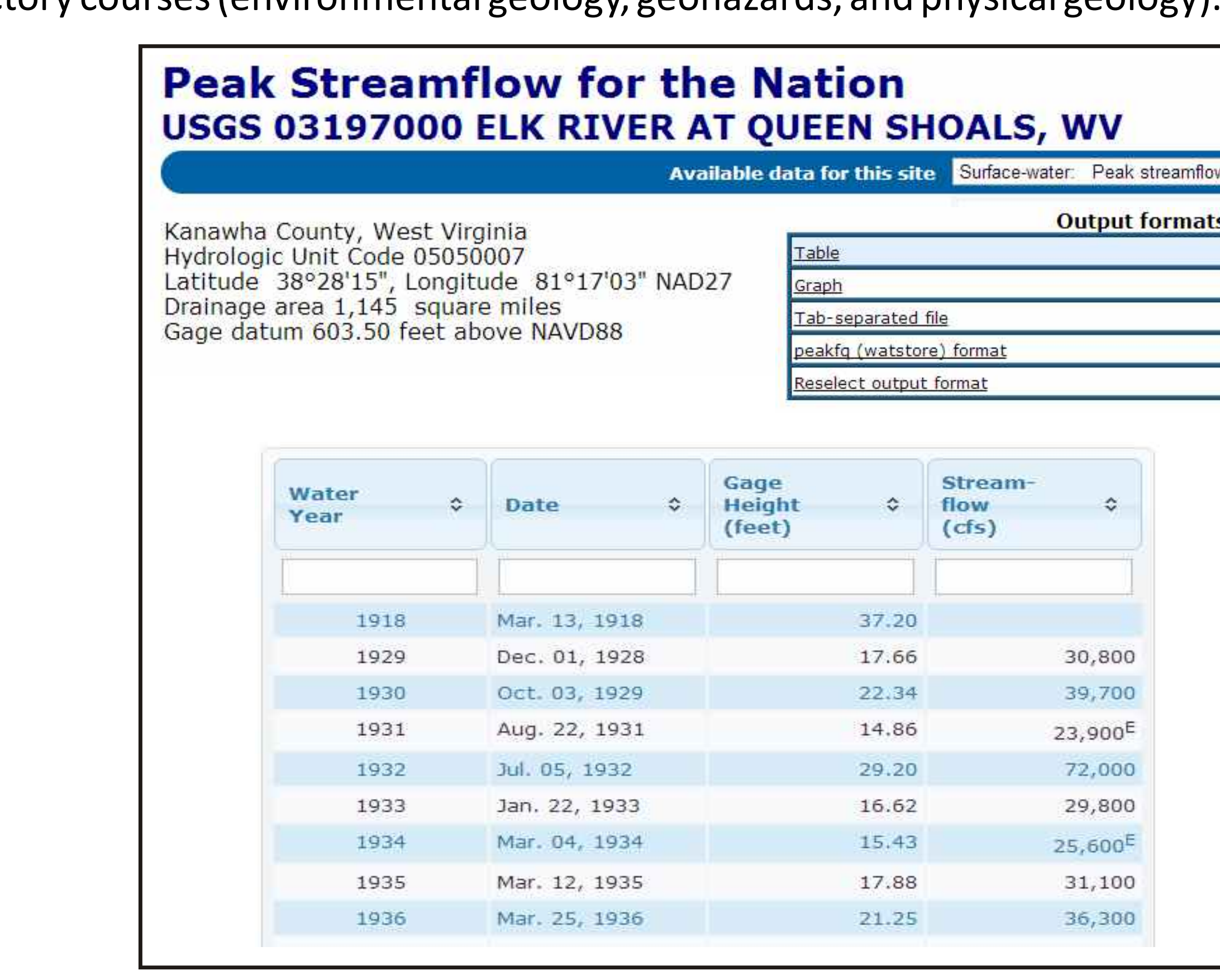

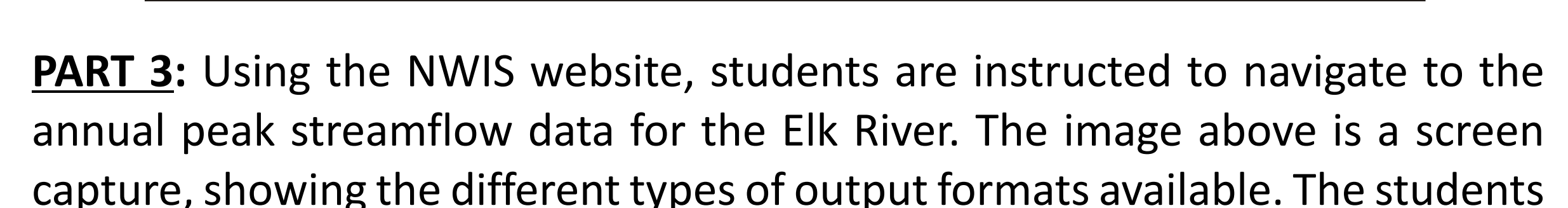

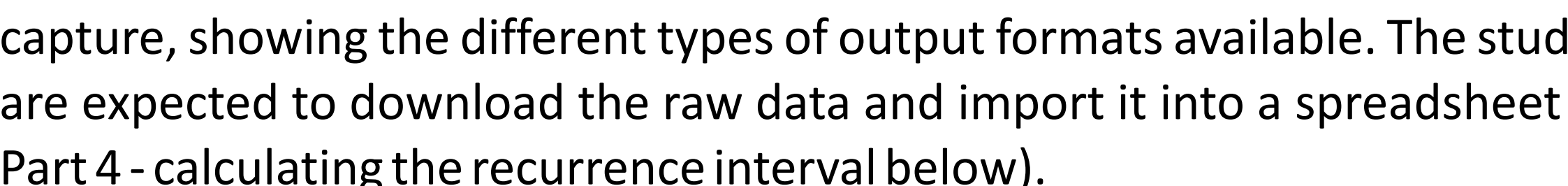

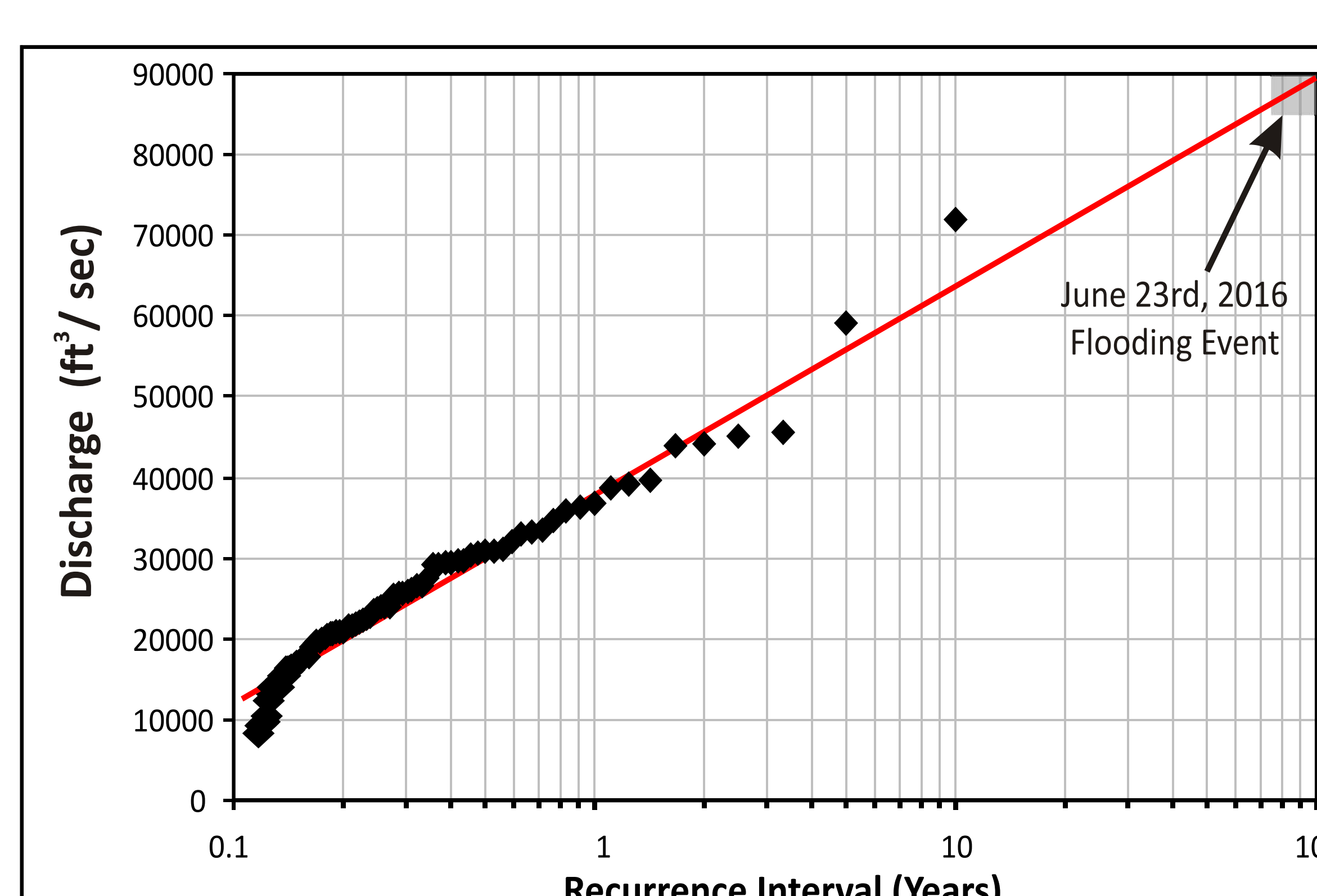

Recurrence Interval (vears)

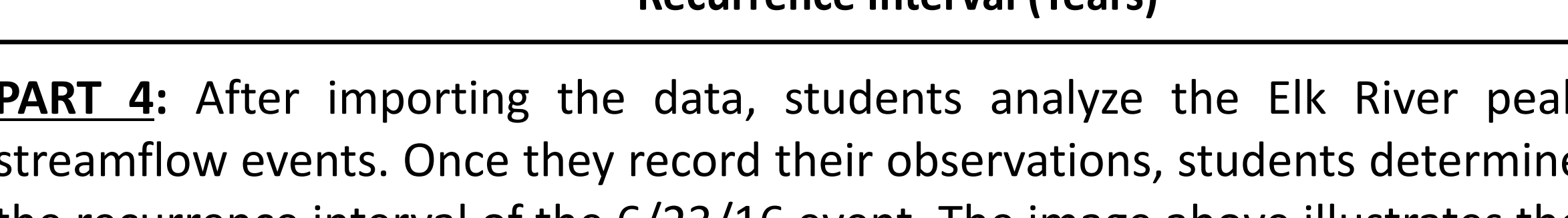

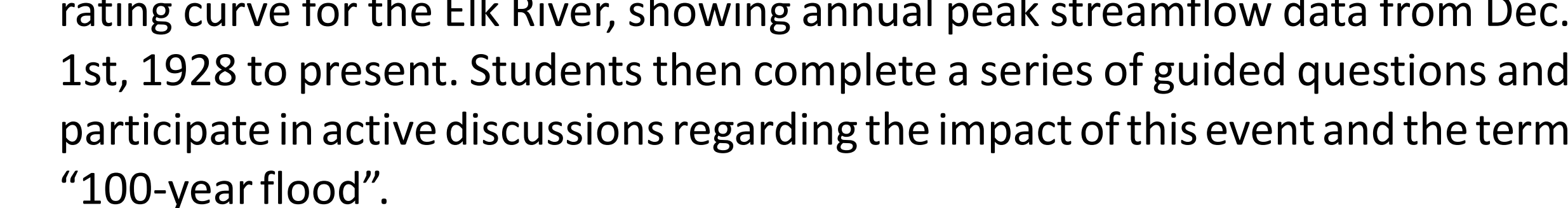

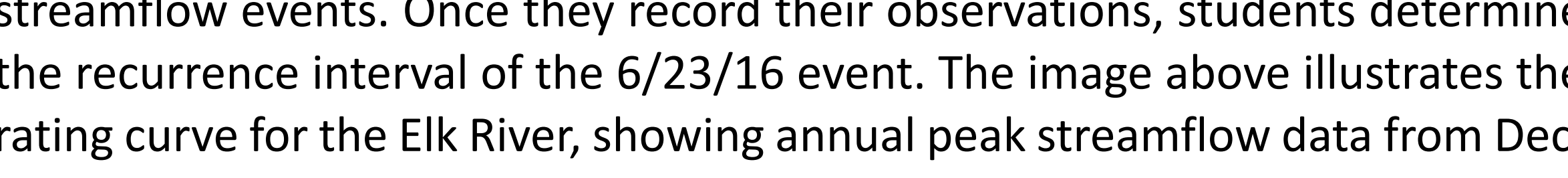

LOWER-DIVISION EXERCISES

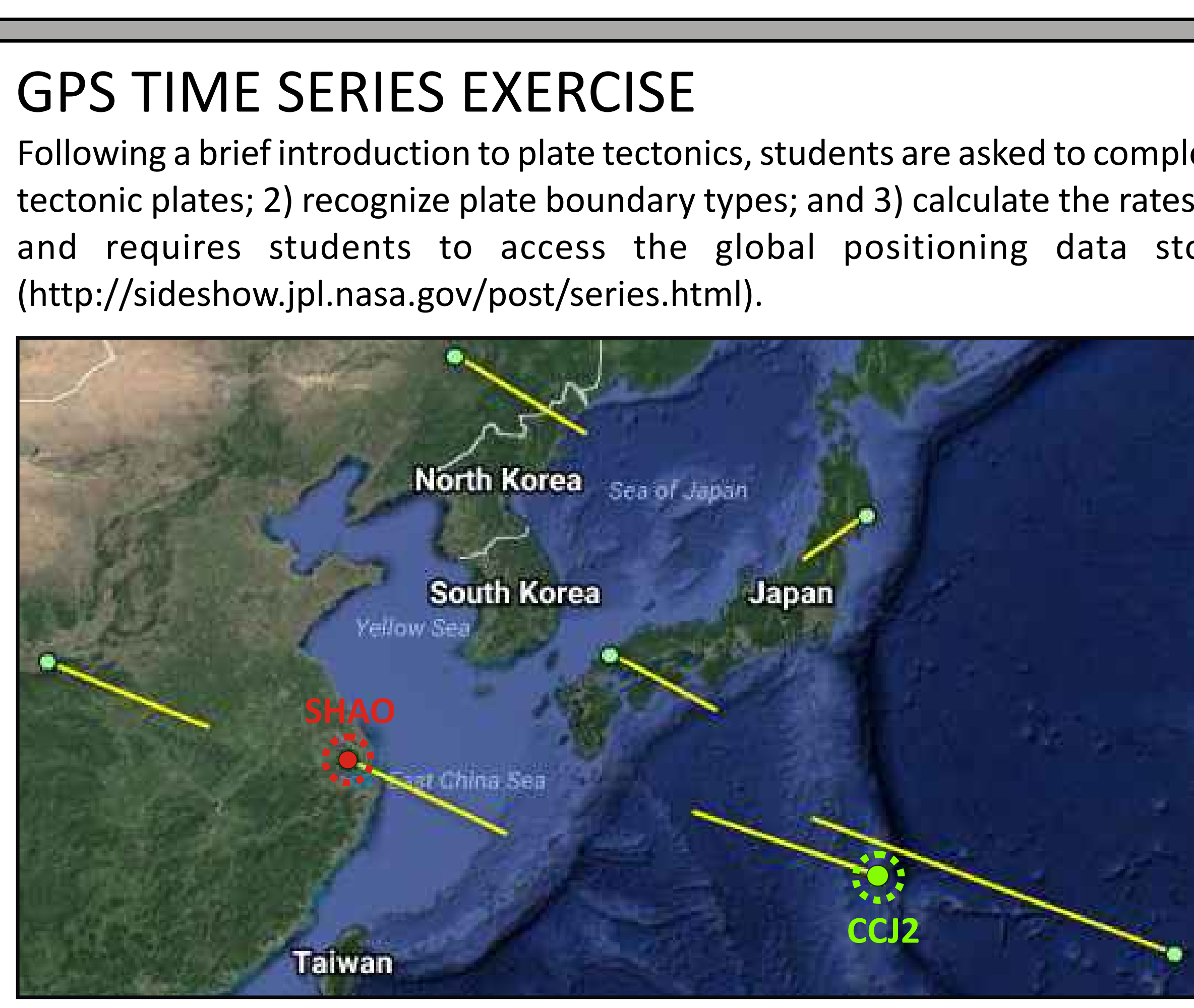

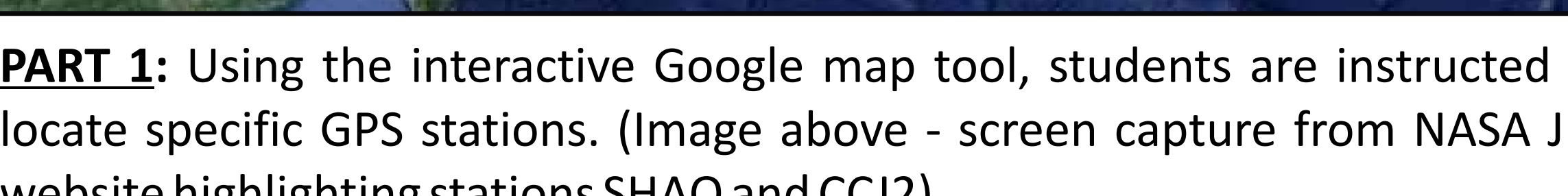

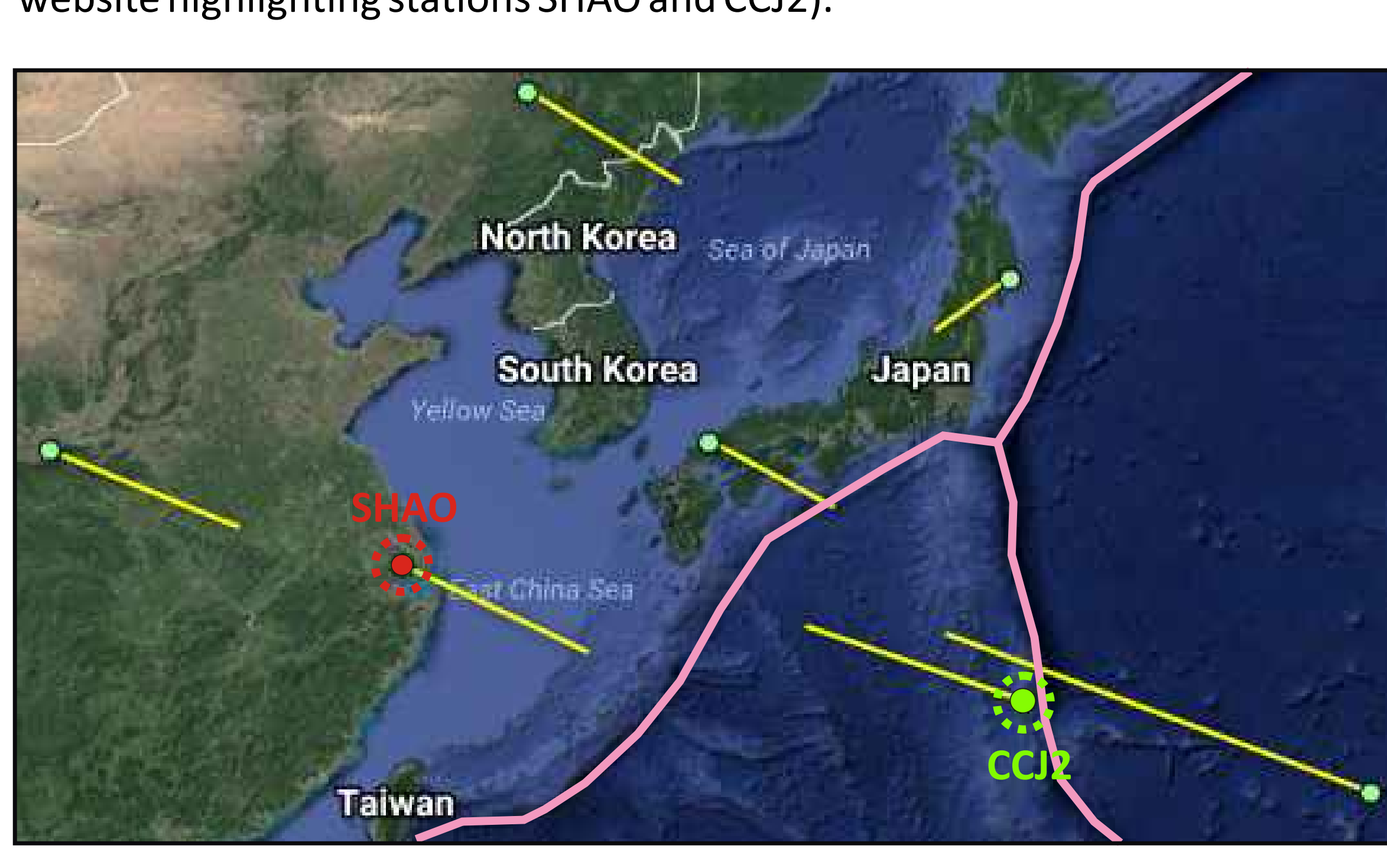

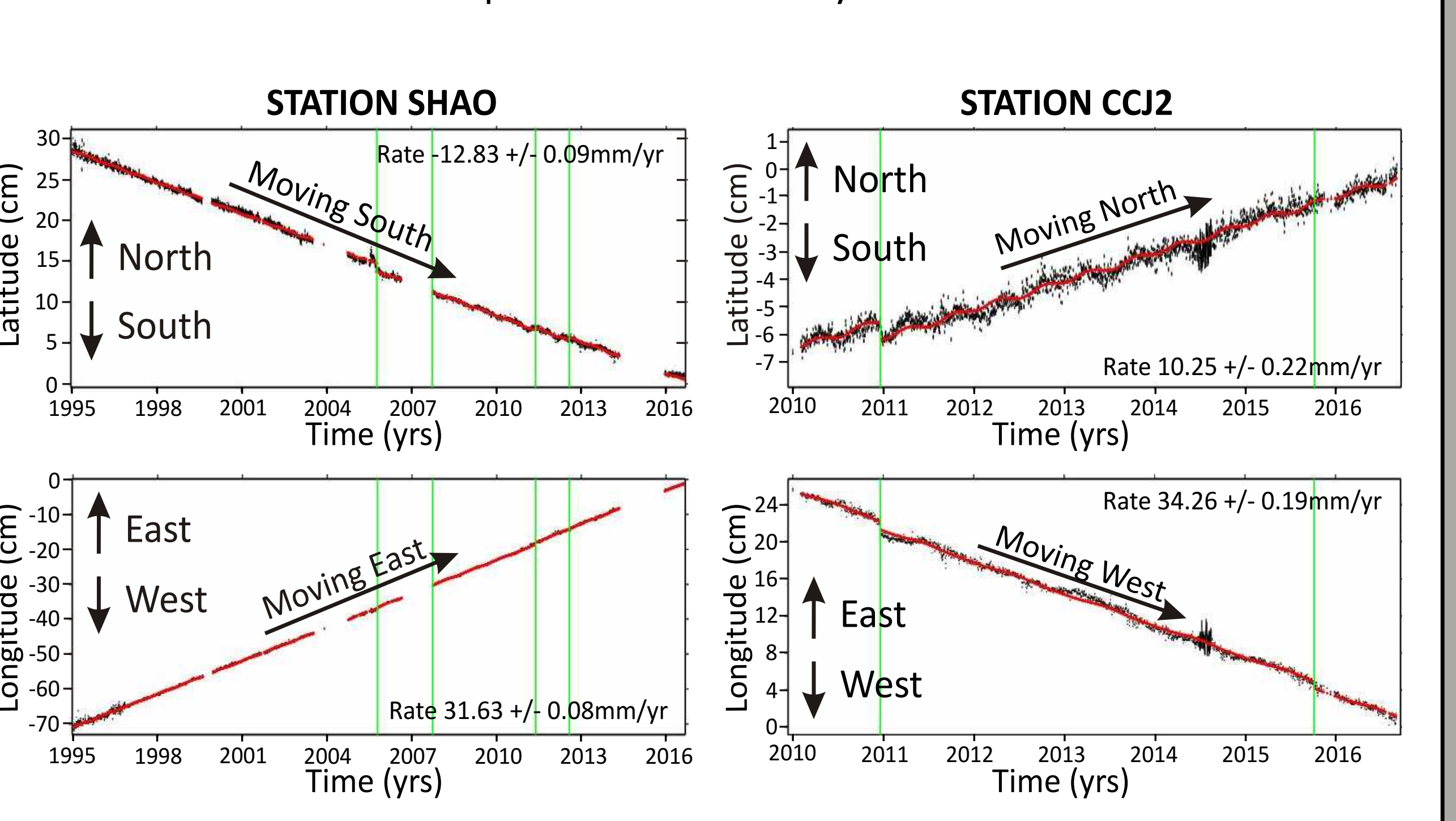

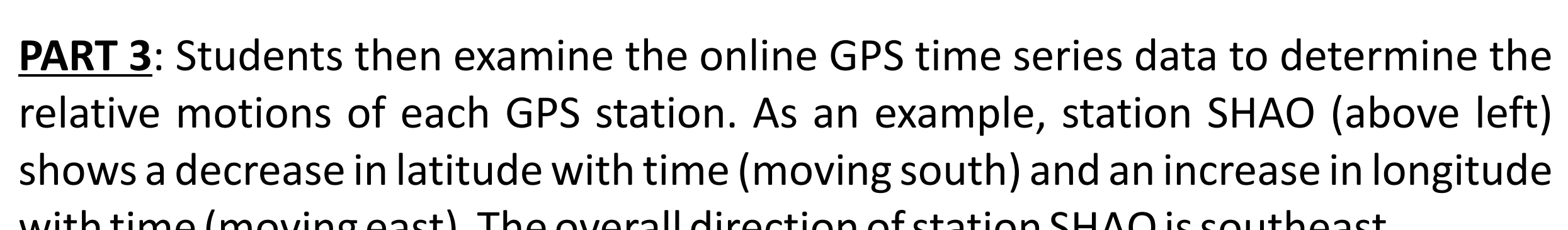

$$
\begin{aligned}
& \text { Station SHAO }
\end{aligned}
$$

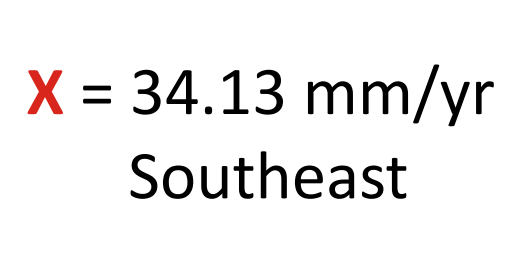

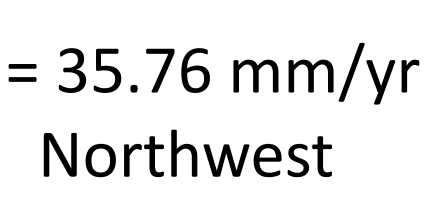

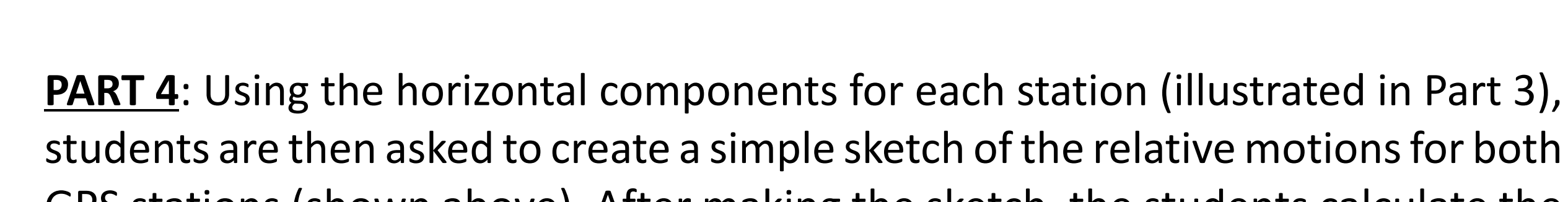

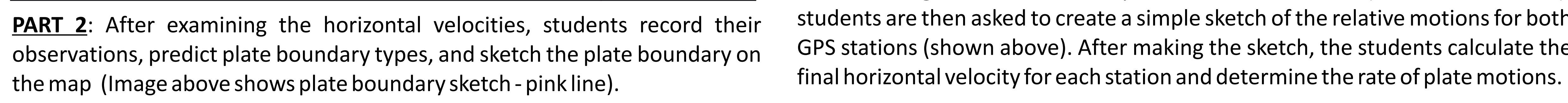
CLIMATE CHANGE EXERCISE

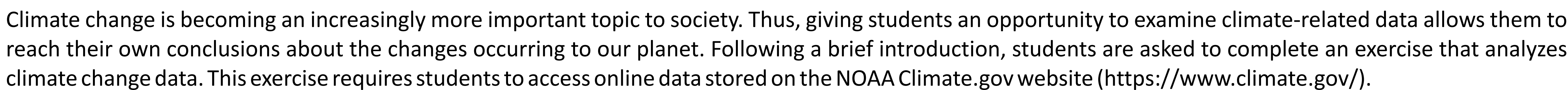

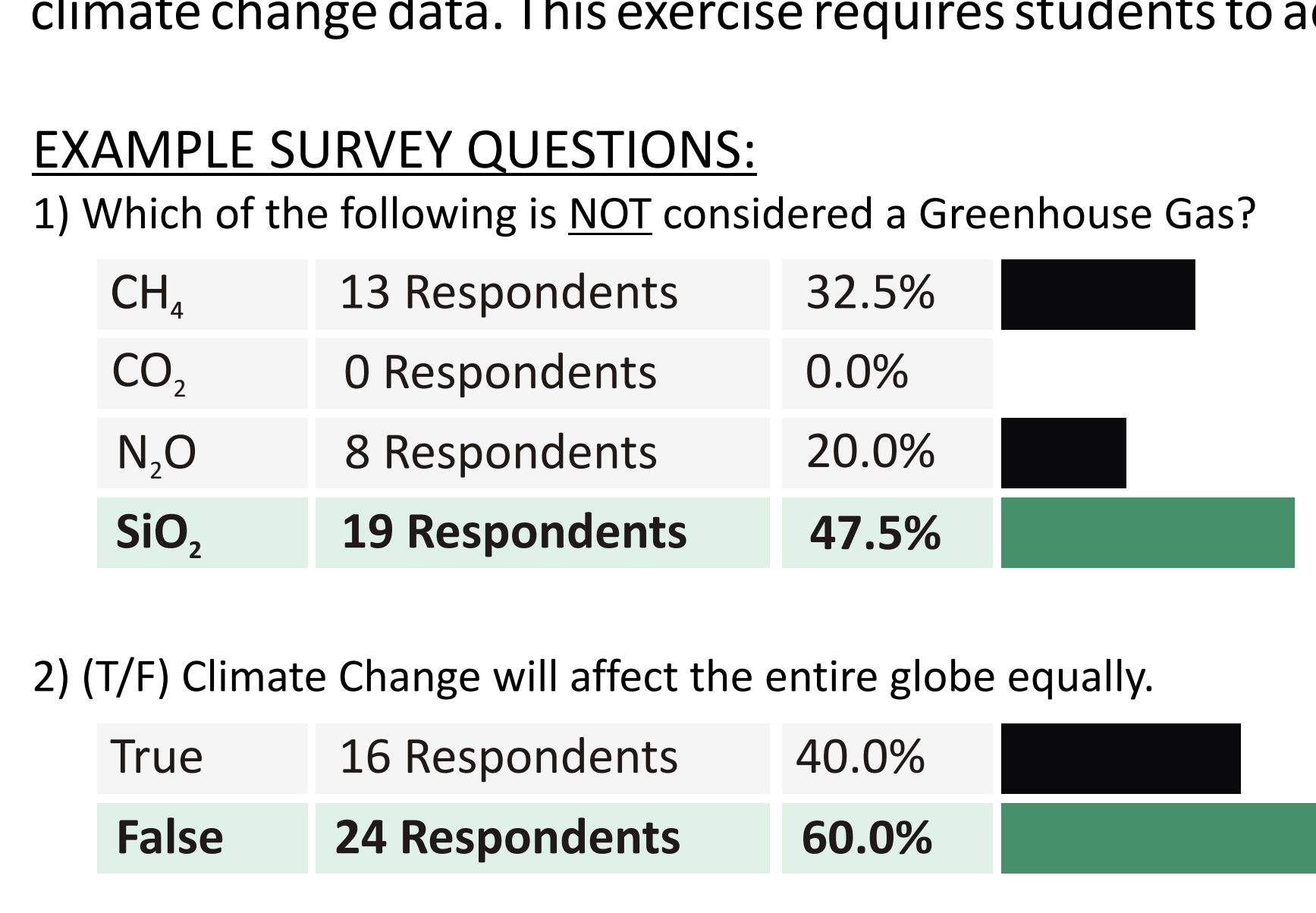

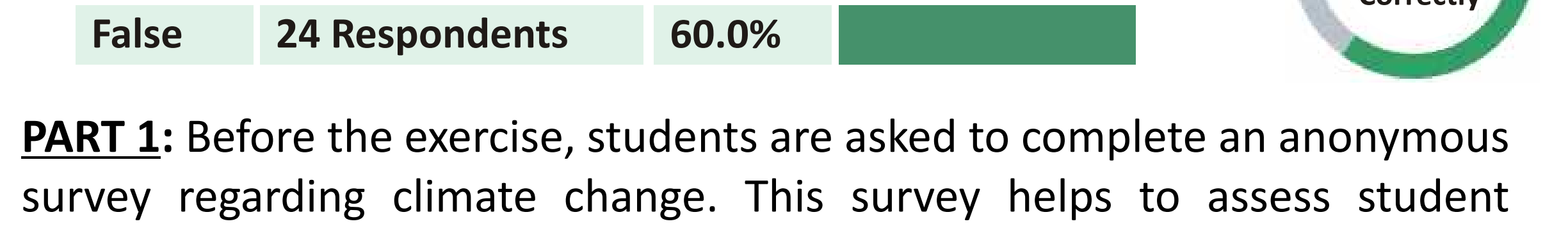

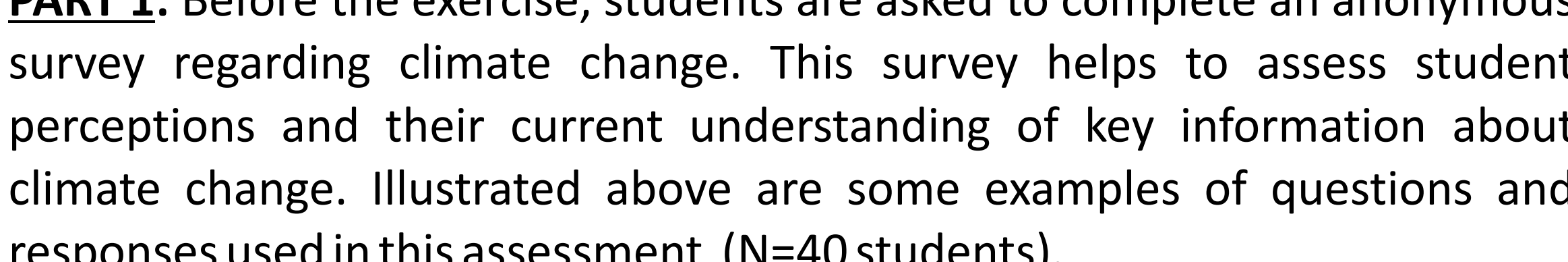

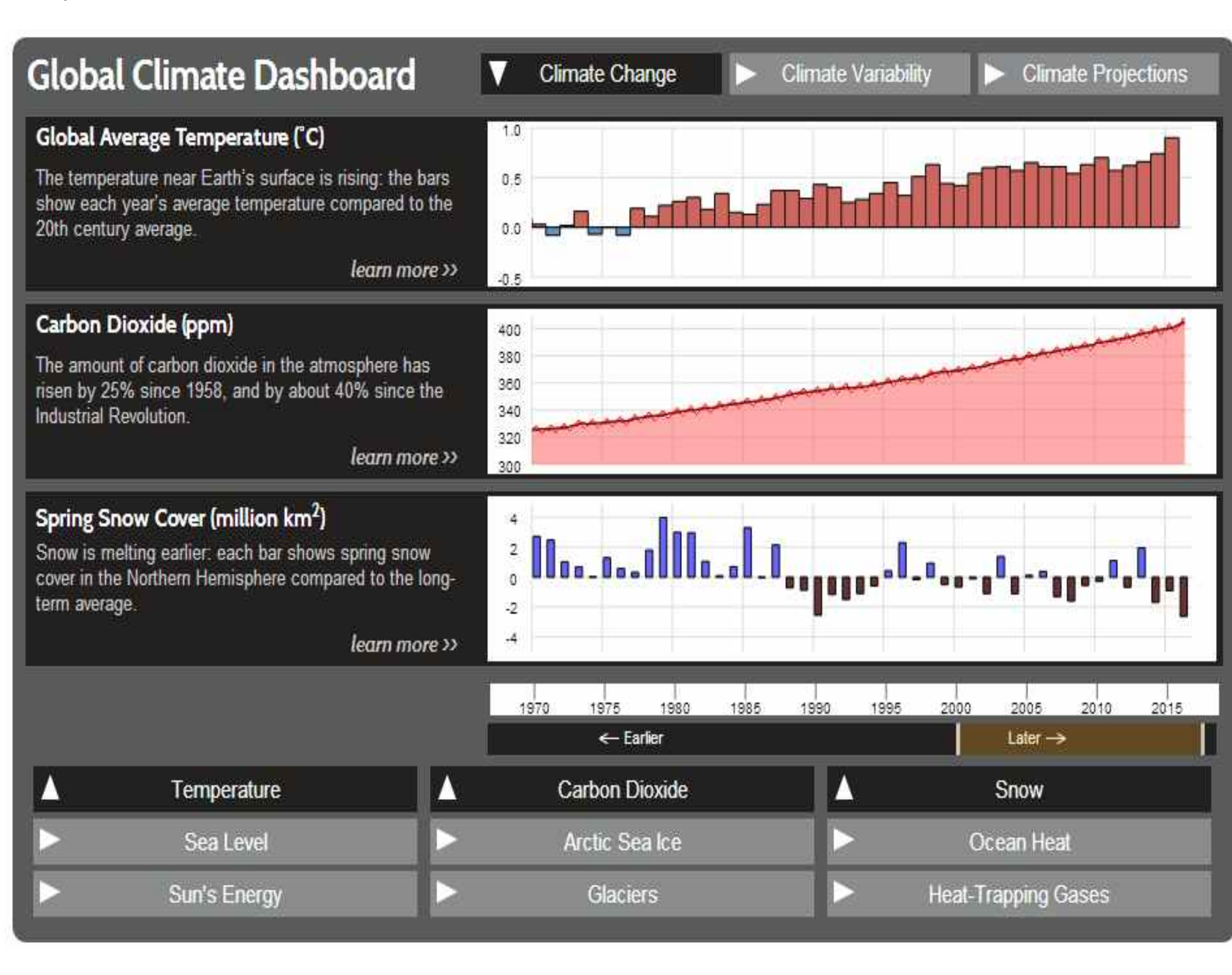

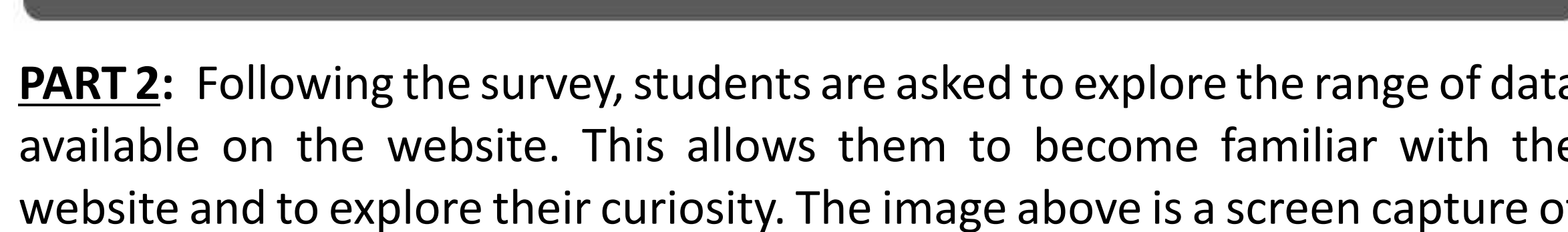

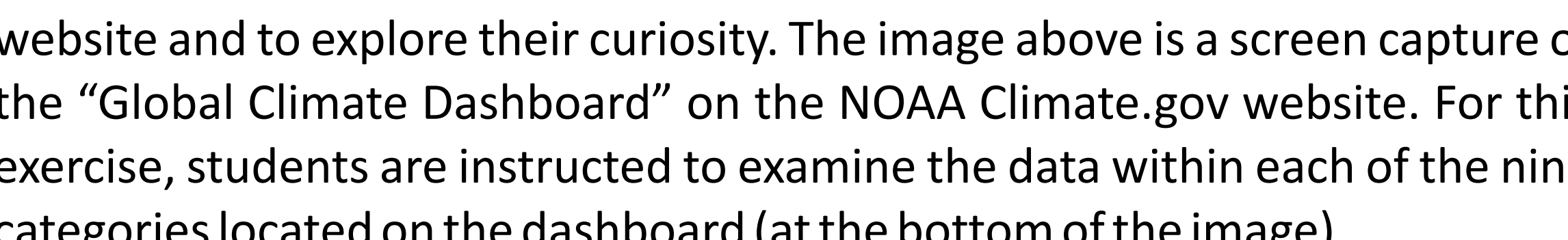

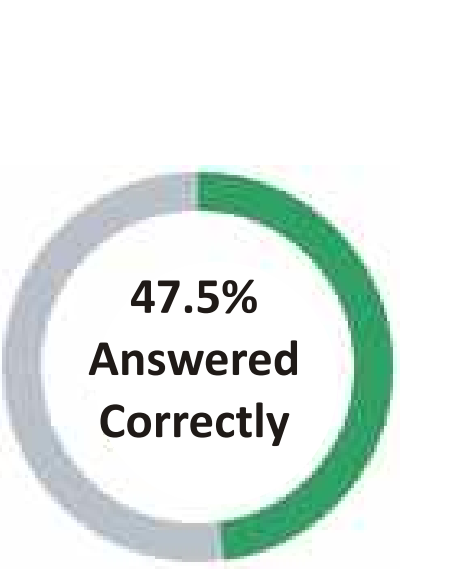

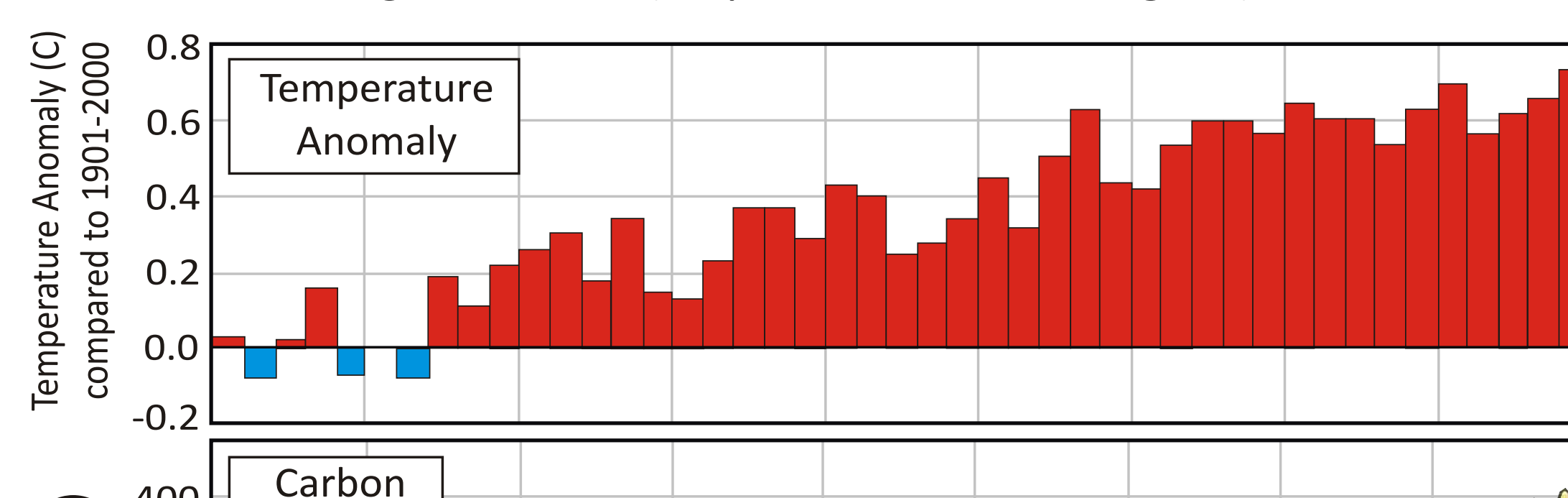

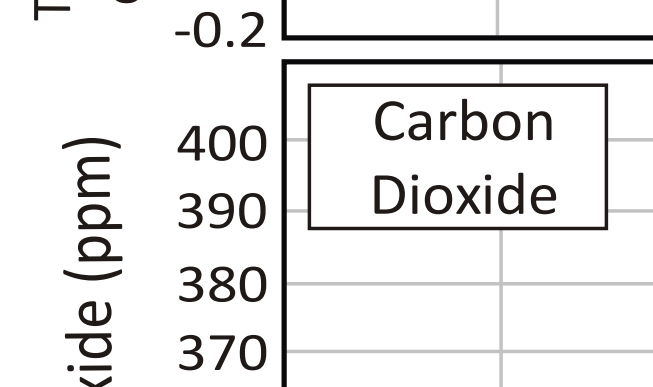

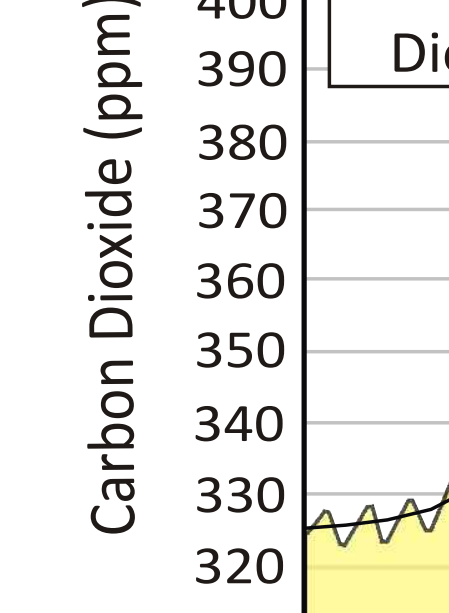

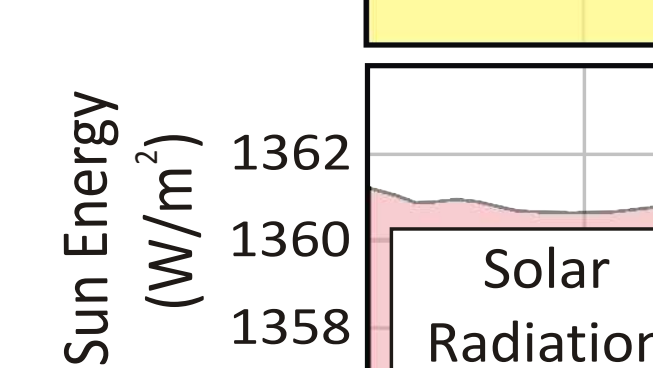

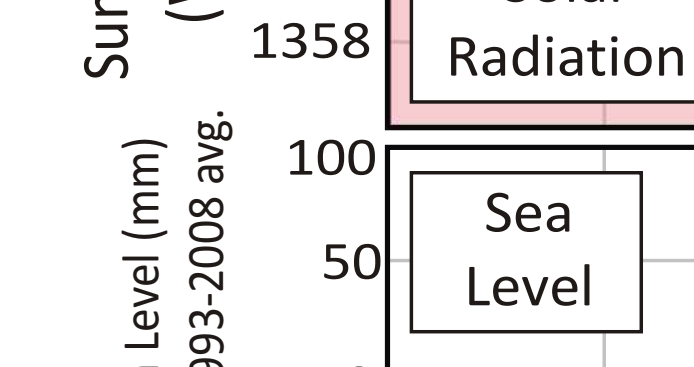

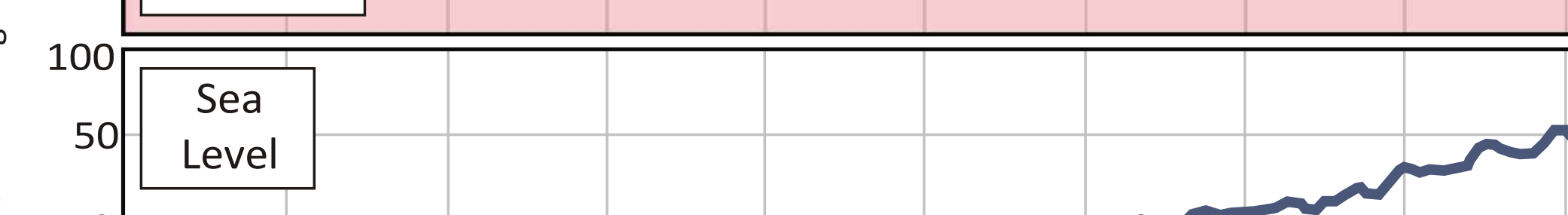

som

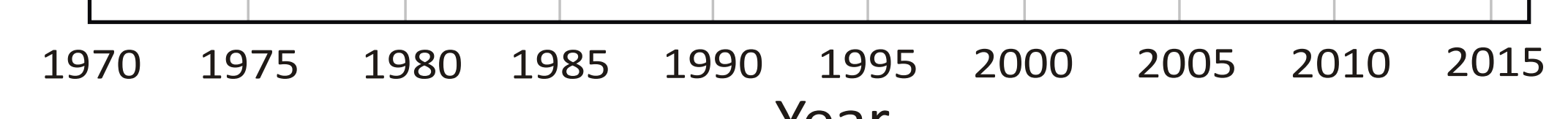

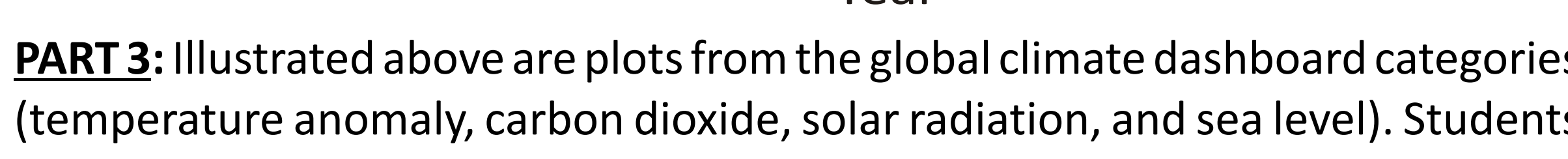

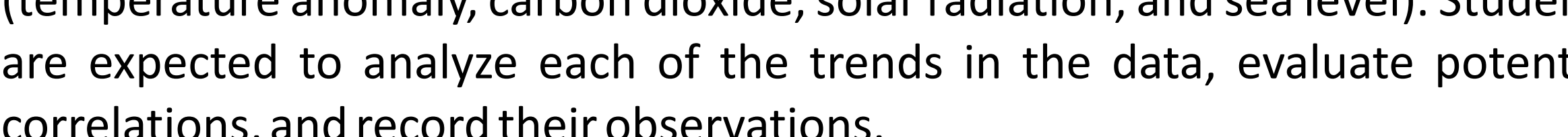

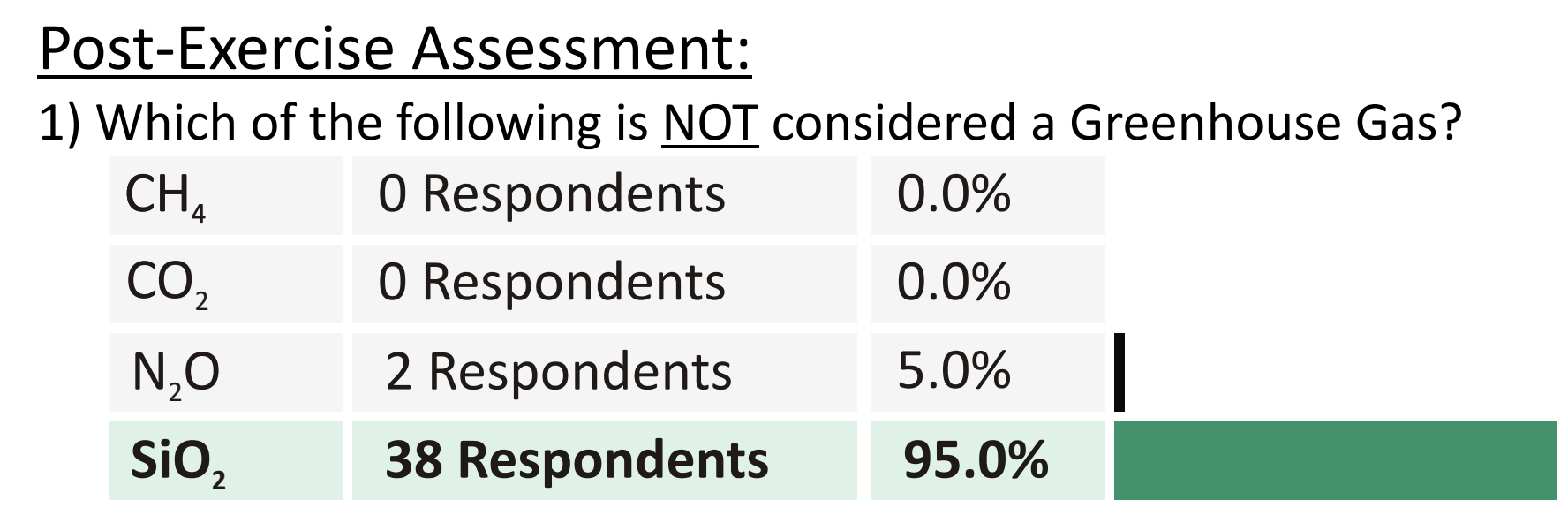

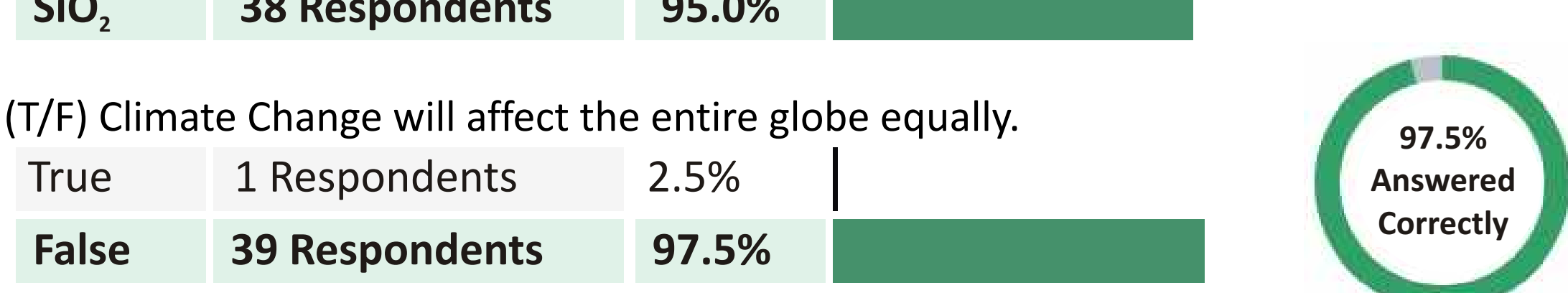

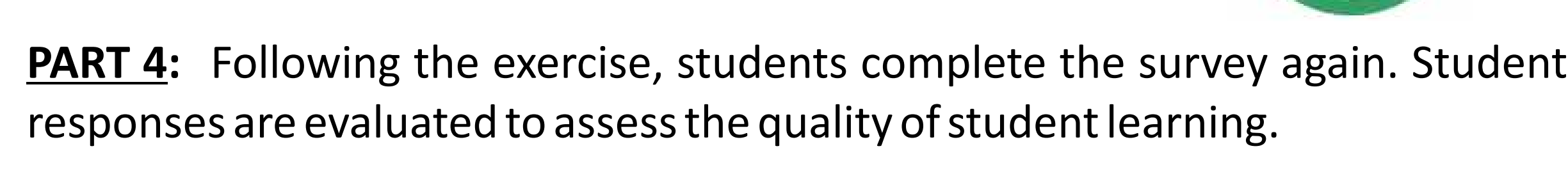

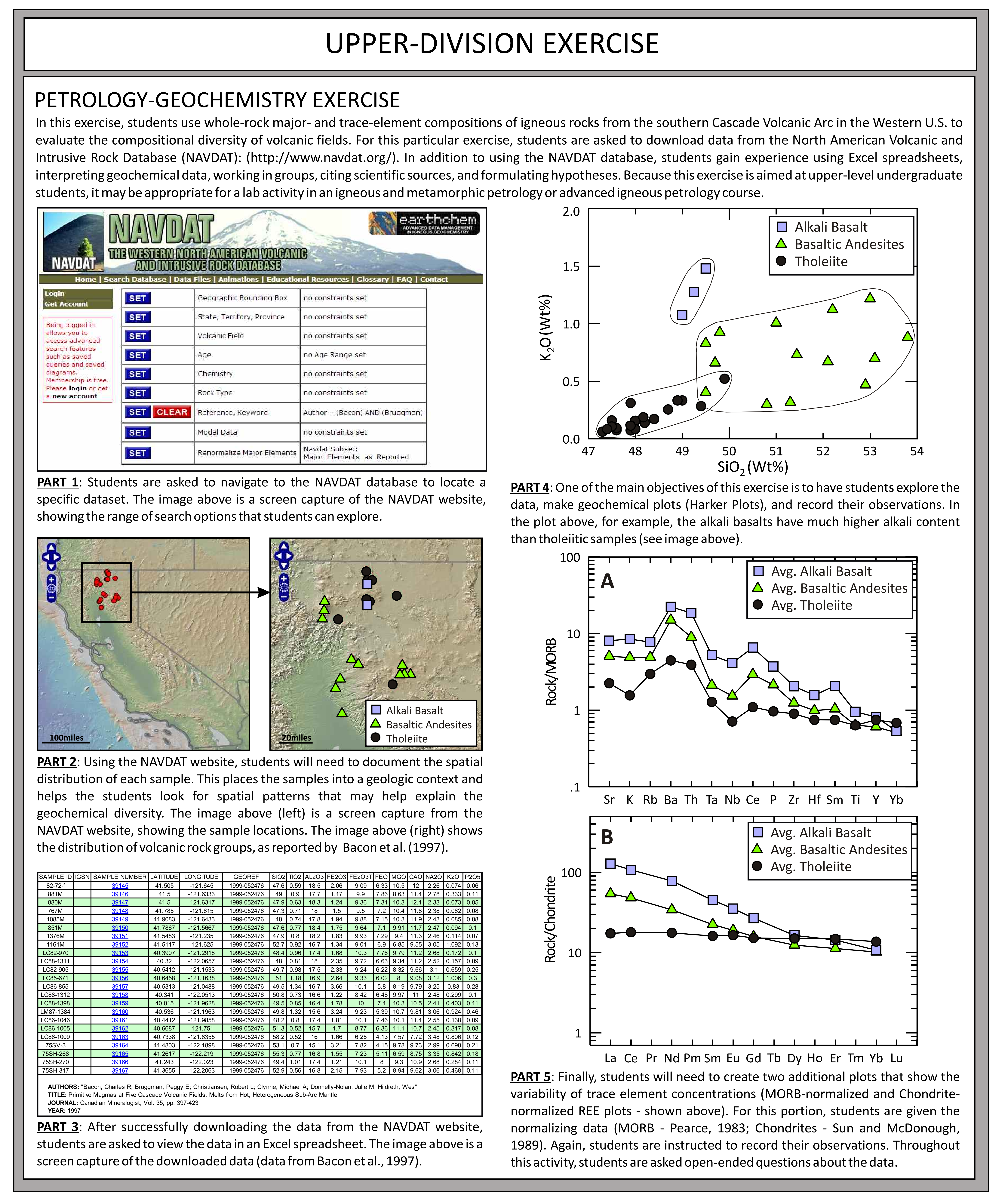

DISCUSSION AND FUTURE DIRECTIONS

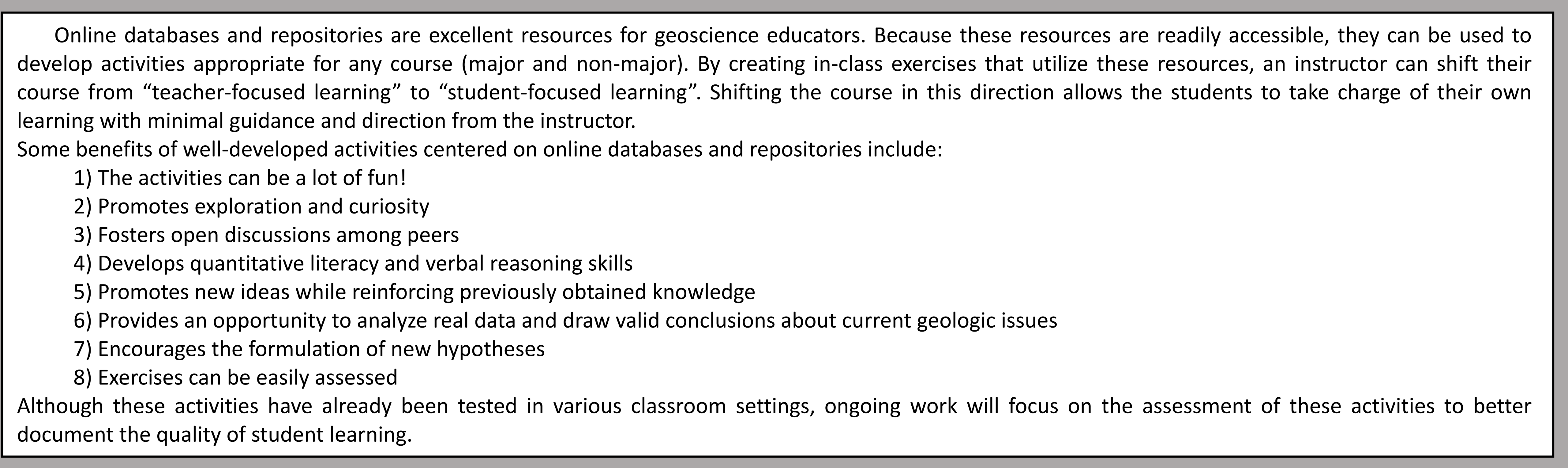

$=$ 